\title{
Testing and Evaluation of Concrete Structures by Non-stationary Thermal Wave Imaging
}

\author{
Geetika Dua and Vanita Arora \\ InfraRed Imaging Laboratory (IRIL), Department of Electrical Engineering, Indian Institute of \\ Technology Ropar, Nangal Road, Rupnagar, Punjab, India-140001 \\ Tel: +91-1881-222118 fax: +91-1881-227078 \\ *ravibabucareiitd@yahoo.co.in
}

\begin{abstract}
The increased usage of concrete structures in building vital nuclear power plants, flyovers in corrosive environment and construction of multi store buildings demand its thorough inspection and evaluation before making them functional. This paper highlights a whole-filed, remote, nondestructive testing and evaluation method based on infrared thermography for visualizing hidden corrosion of rebar in a concrete structure. Results shows for both proposed time and frequency domain transform techniques proves the effectiveness of the adopted approach for identification of corrosion in rebar in the concrete samples.
\end{abstract}

Keywords: Frequency modulation, non-destructive testing, time and frequency domain phase images. 